\title{
Risk factors predicting recurrent small intestinal resection for Crohn's disease of the terminal ileum
}

\author{
HANNA BINDER MD FRCPC, HUGH J FREEMAN MD FRCPC FACP
}

H BINDER, HJ FREEMAN. Risk factors predicting recurrent small intestinal resection for Crohn's disease of the terminal ileum. Can J Gastroenterol $1994 ; 8(3): 193-198$. This study examined potential risk factors for recurrent small intestinal resection in a 'reagent-grade' group of 94 consecutive patients with prior removal of histologically defined Crohn's disease localized to the distal ileum seen by one gastroenterologist at a single teaching hospital. There were 38 males and 56 females ranging in age from 15 to 58 years, with an average length of follow-up of 8.7 years. Of these, $26 \%$ required a second resection for recurrent small intestinal disease. Cumulative reoperation rates in these 25 patients were $18 \%$ at five years and $24 \%$ at 10 years. Univariate and multivariate analyses of multiple demographic, clinical, laboratory and pathological variables revealed two apparent statistically significant independent risk factors for a second intestinal resection: steroid treatment, likely an indirect indication of more severe disease activity; and the presence of an internal fistula, consistent with the emerging concept of a relatively more aggressive clinical form of Crohn's disease.

Key Words: Crohn's disease, Fistula, Ileal resection, Recurrent Crohn's disease, Reoperation

Facteurs de risque et prévisibilité de résection répétée du grêle dans la maladie de Crohn au niveau de l'iléon terminal

RÉSUMÉ : Cette étude a examiné les facteurs de risque potentiels de nouvelles résections du grêle dans un groupe de 94 patients consécutifs de grade réactif, ayant déjà subi une exérèse pour maladie de Crohn histologiquement définie, localisée à la portion distale de l'iléon, observés par un gastro-entérologue dans un seul établissement hospitalier universitaire. Trente-huit patients et 56 patientes, âgés de 15 à 58 ans, chez qui la période de suivi moyenne a été de 8,7 ans. continued on next page

Department of Medicine (Gastroenterology), University of British Columbia and University Hospital, Vancouver, British Columbia

Correspondence and reprints: Dr Hugh Freeman, Head, Gastroenterology, ACU F-137, University Hospital (UBC), 2211 Wesbrook Mall, Vancouver, British Columbia V6T 1W5. Telephone (604) 822-7216 or $822-7235$

Received for publication November 15, 1992. Accepted November 15, 1993
$\mathrm{C}$ ROHN'S DISEASE (CD) APPEARS TO occur through the length of the gastrointestinal tract, with a predilection for the ileum and colon. Microscopic features of $\mathrm{CD}$, such as granuloma, may be detected in up to $20 \%$ or more of serially sectioned mucosal biopsies from normal rectum $(1,2)$, and similar findings have been reported in gastric and duodenal biopsies from patients with ileocolonic involvement (3). In these patients, repeated resections may be done but reappearance of changes associated with $\mathrm{CD}$, usually recognized near the anastomosis, are not necessarily diminished by a wider initial resection (4). Indeed, resection is very unlikely to alter any specific genetic or environmental factor that may have resulted in disease. Thus, it is argued that 'curative' resection is not possible in $\mathrm{CD}$.

Despite these observations, 'recurrence' rates following 'curative' resection for $\mathrm{CD}$ localized to the distal ileum are reported to vary widely, especially, but not exclusively, in the surgical literature (5-11). Critical to this issue, however, are different definitions of 'recurrence'; these may include: redevelopment of clinical symptoms, postoperative radiological or endoscopic changes after removal of all visibly ab- 
D'entre eux, $26 \%$ ont nécessité une deuxième résection pour une récidive de la maladie au niveau du grêle. Les taux cumulatifs de réintervention chez ces 25 patients ont été de $18 \%$ après 5 ans et de $24 \%$ après 10 ans. Les analyses univariées et multivariées de multiples variables démographiques, cliniques, pathologiques et des résultats d'analyses de laboratoire, ont révélé deux facteurs de risque indépendants apparents et statistiquement significatifs à l'égard d'une seconde résection intestinale : le traitement stéroïdien susceptible d'être une indication indirecte d'une activité pathologique plus grave et la présence d'une fistule interne qui concorde avec le concept émergent d'une forme clinique relativement plus agressive de la maladie de Crohn.

normal intestine, or a need for repeated surgical treatment. There is evidence, for example, that endoscopic changes may occur within one year of a 'curative' ileal resection, but these macroscopic changes (eg, aphthous, linear or serpiginous ulcers) correlate poorly with 'specific' microscopic changes (eg, granuloma) and patient symptoms (12). Although direct visualization may improve the clinician's appreciation for events in the evolution of this disease, the frequent requirement for recurrent small intestinal resection remains a significant and most frustrating clinical event for the patient with $\mathrm{CD}$.

In the present study, risk factors for recurrent small intestinal resection were explored in patients with prior removal of $\mathrm{CD}$ localized in the distal ileum. Ninety-four 'reagent-grade' patients were identified and statistically evaluated to determine possible clinical, laboratory or pathological features present at initial surgery that might have predicted a further small intestinal resection.

\section{PATIENTS AND METHODS}

In-patient and/or out-patient clinical records of approximately 1500 adults with inflammatory bowel disease followed by one of the authors for at least one year at the campus site of the University Hospital, Vancouver, British Columbia, were examined to identify all patients with $\mathrm{CD}$ who had a prior definitive (ablative) terminal ileal resection. The present study focused on the ileum since this site is most commonly involved in $\mathrm{CD}$. A definitive operation for $\mathrm{CD}$ was defined as a resection of all macroscopically diseased distal small intestine (13). For most patients, prior radiological, endoscopic and histological studies were available, as well as previous operative records and pathological findings. Histological reevaluation of prior biopsies and resected specimens were done to ensure that histopathological criteria characteristic of $\mathrm{CD}$ were present (14).

In order to define a 'reagent-grade' group of $\mathrm{CD}$ patients, only those with ileal disease alone were included. Disease elsewhere in the gastrointestinal tract identified by radiological or endoscopic studies before or during the ileal resection resulted in patient exclusion (except for perianal disease). In particular, patients were excluded if there was a history of an 'extended' right hemicolectomy for concomitant colonic involvement, prior nonablative surgery for $\mathrm{CD}$, such as gastroenterostomy, stricturoplasty, small intestinal bypass or exclusion, or an appendectomy for granulomatous appendicitis (15). Finally, patients were excluded if there was a positive fecal examination for a known parasite or bacterial pathogen, such as Yersinia species $(16,17)$, a positive fecal toxin(s) assay for Clostridium difficile $(18,19)$ or another possible noninfectious cause for ileal disease, ie, ischemic stricture or malignancy $(20,21)$.

Ninety-four consecutive patients were identified with a prior terminal ileal resection that fulfilled all of these previously defined criteria for subsequent statistical analyses. Average length of follow-up for this patient group was 8.7 years. There were 38 males and 56 females, average age 29 years (range 15 to 58 ). Indications for the small intestinal resection included failed medical therapy associated with recurrent obstructive episodes and/or septic complications including fistula and/or abscess formation.

Postoperative recurrent surgery rates were analyzed with Kaplan-Meier survival estimates based on standard actuarial techniques used elsewhere for postoperative follow-up of patients with $\mathrm{CD}$ (22-26). Multiple demographic, clinical and laboratory variables present at primary resection were tabulated using a modification of an IBM PC computer program for patients with inflammatory bowel disease (IBD-3 Database System, De Dannan Systems).

To identify possible predictive or risk factors for recurrent small intestinal resection, comparisons were done between the group requiring a second resection (repeat resection) and the group not requiring a second resection (no repeat resection). These were determined by means of Wilcoxon and logrank tests based on methods described elsewhere (26). The parameters studied included demographic data (sex, age at diagnosis of $\mathrm{CD}$, age at first resection), preoperative clinical findings (diarrhea, fever, perianal disease, extraintestinal features), treatment (including steroids), laboratory studies (hemoglobin, erythrocyte sedimentation rate, serum albumin), rectal biopsy and operative findings, including granulomatous inflammation and internal fistulas. Each parameter was scored and analyzed as the main variable for influence on the risk of a second small bowel resection (univariate logrank and Wilcoxon tests) and as covariable (stepwise sequence of logrank and Wilcoxon tests) using a computer program (SAS, lifetest procedure, North Carolina). These methods have been applied previously by other investigators to analyze the effect of specific demographic and preoperative clinical parameters on disease recurrence in $\mathrm{CD}$ (26).

\section{RESULTS}

Reoperation rates for study group: Twenty-five of the 94 patients (26\%) ultimately required a second resection for recurrent small intestinal disease. Indications for the second resection were similar to those for the initial re- 
section. The group requiring a second resection included 13 males and $12 \mathrm{fe}$ males, average age 28 years (range 17 to $57)$, while the group not requiring a second resection included 25 males and 44 females, average age 31.5 years (range 16 to 58). The cumulative reoperation rate observed in these $94 \mathrm{pa}$ tients with an initial resection for $\mathrm{CD}$ of the terminal ileum was $18 \%$ at five years and $24 \%$ at 10 years. Figure 1 plots these data as cumulative reoperation rate defined as patients with recurrent disease treated by resection compared with patients at risk during that year. Unlike crude recurrence rates, this method corrects for varying lengths of follow-up among individual patients (22-25). These results are similar to data published elsewhere on patients with small bowel disease and the requirement for a second resection of preanastomotic recurrent disease in histologically proven CD of the distal ileum $(22,27)$.

Identity parameters for patient groups: Sex and mean age at the time of establishment of $\mathrm{CD}$ diagnosis as well as the mean age at the time of the initial small intestinal resection are shown in Table 1 for both patient groups (repeat resection and no repeat resection). For these study groups, no significant differences were observed.

Clinical features of patient groups: Scores for selected clinical features, intestinal and extra-intestinal complications as well as treatment regimens observed in the repeat resection and no repeat resection patient groups are compared in Table 2. Although perianal disease was seen less frequently in the patient group requiring a further ileal resection, no statistically significant differences in recorded clinical features, as well as intestinal and extraintestinal complications for the two patient groups, were evident. Different pharmacological treatments were provided before the initial resection, but only the use of corticosteroids alone or combined with another medication appeared to be a statistically significant predictive factor $(\mathrm{P}<0.05)$ for repeated small intestinal resection. Preoperative total parenteral nutrition was required by patients in both the repeat resection and no repeat resection groups, and its

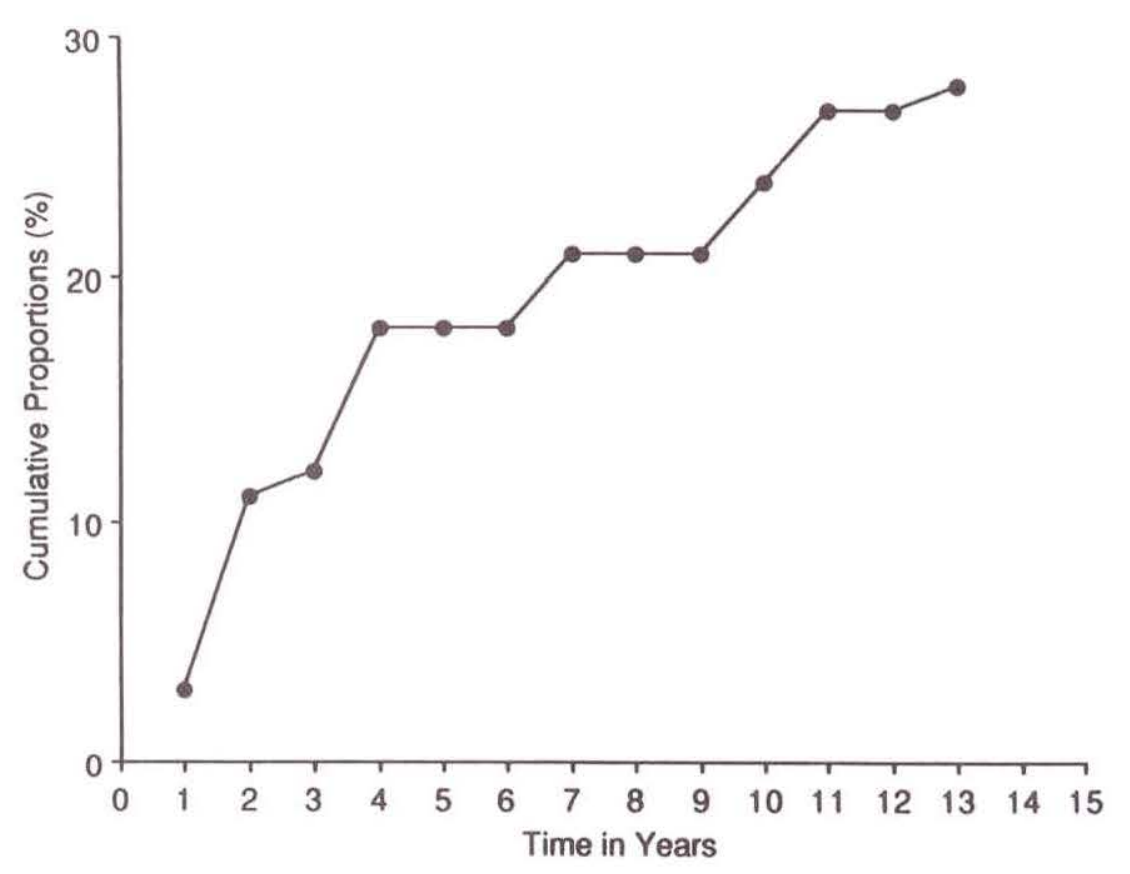

Figure 1) Cumulative reoperation rates or proportions (\%) in 94 patients with a prior ileal resection for Crohn's disease of the terminal ileum

TABLE 1

Sex and age of patient groups

\begin{tabular}{lcc}
\hline & Repeat resection & No repeat resection \\
\hline Sex (male:female) & $13: 12$ & $25: 44$ \\
Age (mean \pm SEM) at diagnosis & $25.2 \pm 2.05$ & $27.4 \pm 1.22$ \\
Age (mean \pm SEM) at resection & $28.0 \pm 3.06$ & $31.5 \pm 4.03$ \\
\hline
\end{tabular}

Comparisons for ages between repeat resection and no repeat resection were not significant

TABLE 2

Clinical features of patient groups

\begin{tabular}{lcc}
\hline & Repeat resection & No repeat resection \\
\hline Abdominal pain (mean \pm SEM) & $3.00 \pm 0.00$ & $2.98 \pm 0.01$ \\
Diarrhea & $2.16 \pm 0.18$ & $2.22 \pm 0.12$ \\
Anorexia & $2.00 \pm 0.20$ & $1.70 \pm 0.13$ \\
Weight loss & $2.10 \pm 0.21$ & $1.90 \pm 0.13$ \\
Fever & $0.88 \pm 0.18$ & $0.77 \pm 0.12$ \\
Perianal disease & $0.56 \pm 0.20$ & $0.97 \pm 0.15$ \\
Anal fissure & $0.17 \pm 0.08$ & $0.28 \pm 0.05$ \\
Fistula & $0.13 \pm 0.07$ & $0.11 \pm 0.03$ \\
Abscess & $0.13 \pm 0.07$ & $0.11 \pm 0.04$ \\
Arthritis & $0.56 \pm 0.20$ & $0.44 \pm 0.10$ \\
Other extraintestinal features & $0.36 \pm 0.11$ & $0.28 \pm 0.06$ \\
Steroid treatment & $0.65 \pm 0.11$ & $0.32 \pm 0.06 *$ \\
Preoperative parenteral nutrition & $0.16 \pm 0.07$ & $0.17 \pm 0.04$
\end{tabular}

Numbers represent scores (mean \pm SEM) as described elsewhere (26), "P<0.05; all other comparisons between the groups were not significant

use at the time of the initial resection was not predictive of recurrent disease. Laboratory and endoscopic biopsy studies: Table 3 lists selected laboratory parameters and the results of serially sectioned rectal biopsies done in the two patient groups (repeat resection and no repeat resection). Hemoglobin 
TABLE 3

Laboratory parameters

\begin{tabular}{lcc}
\hline & Repeat resection & No repeat resection \\
\hline Hemoglobin $(\mathrm{g} / \mathrm{L})$ & $131 \pm 3.48$ & $129 \pm 1.89$ \\
Erythrocyte sedimentation rate $(\mathrm{mm} / \mathrm{h})$ & $20 \pm 5.18$ & $24 \pm 3.05$ \\
Serum albumin $(\mathrm{g} / \mathrm{L})$ & $37 \pm 1.66$ & $38 \pm 0.68$ \\
Rectal biopsy inflammation & $0.05 \pm 0.05$ & $0.27 \pm 0.05^{\star}$ \\
Rectal biopsy granuloma & $0.0 \pm 0.0$ & $0.06 \pm 0.03$ \\
\hline
\end{tabular}

Values are mean \pm SEM. Comparisons between the groups were not significant, except for rectal biopsy inflammation, $P \leq 0.01$

\section{TABLE 4}

\section{Surgical pathology findings}

\begin{tabular}{lcc}
\hline & Repeat resection & No repeat resection \\
\hline Small bowel obstruction & $0.88 \pm 0.06$ & $0.86 \pm 0.04$ \\
Fistula & $0.45 \pm 0.10$ & $0.23 \pm 0.05^{*}$ \\
Enteroenteric fistula & $0.37 \pm 0.10$ & $0.22 \pm 0.05$ \\
Enterocutaneous fistula & $0.12 \pm 0.07$ & $0.04 \pm 0.02$ \\
Enterovesical fistula & $0.04 \pm 0.04$ & $0.03 \pm 0.02$ \\
Specimen granuloma & $0.46 \pm 0.13$ & $0.56 \pm 0.06$
\end{tabular}

Values are mean $\pm S E M . \cdot P<0.01$; all other comparisons between the groups were not significant

value, erythrocyte sedimentation rate and serum albumin levels were similar between the groups. As noted above, all patients with macroscopically visible changes seen at endoscopy, including sigmoidoscopy, were excluded. In spite of this, rectal biopsies for microscopic alterations were routinely performed in patients even if no endoscopic abnormality was evident. 'Nonspecific' inflammatory changes or more 'specific' granulomatous inflammatory changes in rectal mucosal biopsies (in the absence of macroscopically visible changes) were seen in the patients described in this study, similar to findings reported elsewhere $(1,2)$. In this study, scores for microscopic inflammation, but not granulomas, were statistically greater in the group not requiring a second small intestinal resection $(\mathrm{P} \leq 0.01)$.

Pathological findings for initial resection: As shown in Table 4, the principal indication for the initial surgical resection in both patient groups was a small intestinal obstruction. The ileal resection specimens had similar histological features in both groups, including granuloma. In this study, the presence of a fistula, confirmed pathologically, was more often associated with a higher risk for recurrent small intestinal resec- tion $(\mathrm{P}<0.01)$; however, comparisons for different fistula entry points from the small intestine did not reveal a statistically significant predominant site (ie, intestine, skin, bladder) for the repeat resection and no repeat resection groups.

\section{DISCUSSION}

One of the most important clinical issues facing the patient with $\mathrm{CD}$ is the frequent requirement for repeated resections of diseased small intestine. There is little doubt that recurrent disease and reoperation significantly affect the quality of the patient's life and result in a significant risk of increased morbidity, and even mortality (28). The present study evaluated a reagentgrade group of patients with a prior complete curative small intestinal resection for $\mathrm{CD}$ localized to the distal ileum to determine possible risk factors for recurrent resection. The cumulative (rather than crude) reoperation rates observed in the present report $-18 \%$ at five years and $24 \%$ at 10 years - are very similar to results in other comparably large studies using actuarial methods $(29,30)$ to correct for the varying lengths of follow-up for individual patients with a second small bowel resection in histologically proven $\mathrm{CD}$ of the ileum. In one study of 73 patients, for example, Lennard-Jones et al (22) reported virtually identical reoperation rates of $16 \%$ at five years and $26 \%$ at 10 years, while in another study, Lock et al's (27) examination of the role of disease location in the determination of reoperation rates in 108 patients with small bowel disease only illustrated a cumulative risk of less than $20 \%$ at five years and less than $35 \%$ at 10 years. Although the lower cumulative reoperation rates in the present report appear to contrast with some other studies $(11,31)$, these included earlier, essentially historical data from patients with concomitant colonic disease or, alternatively, a prior bypass or diversion procedure. Thus, the reagent-grade patients described in this report from a single teaching hospital practice in Canada had similar clinical features and rates of recurrence compared with those described elsewhere from tertiary-care referral centres with a particular interest in inflammatory bowel disease.

In the present study, univariate and multivariate analyses of multiple demographic, clinical, laboratory and pathological variables were done. Two factors appeared to be significantly correlated with the requirement for a second resection in this reagent-grade group of patients with an initial ileal resection for histologically confirmed $\mathrm{CD}$ confined to the distal small intestine: steroid treatment and the presence of an internal fistula. Although a previous investigation identified a trend towards a higher risk of recurrence in patients receiving medical treatment preoperatively (32), corticosteroid therapy or other forms of nonsurgical treatment before the initial resection have not been previously viewed as independent risk factors for a subsequent resection. Possibly, the finding of steroid use before the initial resection is simply an indirect indication of more severe disease activity preceding the initial surgical procedure, compared with those patients who did not require steroids $(25,26,33-35)$. The present study also indicated that an internal fistula is a significant risk factor in those patients requiring a second or repeat small intestinal resection. Simi- 
lar findings were suggested in a study from the Cleveland Clinic (13), although the presence of an internal fistula did not apparently achieve statistical significance for disease confined to the small intestine. In a subsequent study, however, Greenstein and colleagues (36) reported that an initial small bowel resection done for a perforating indication, such as a fistula, was more often followed by a second resection for a similar perforating indi-

ACKNOWLEDGEMENTS: The authors acknowledge Dr M Piaseczny from the AIDS/HIV Clinical Trials Center, St Paul's Hospital, Vancouver, British Columbia, for his assistance in statistical methods and analysis of the data in this study.

\section{REFERENCES}

1. Rotterdam H, Korelitz BI, Sommers SC. Microgranulomas in grossly normal rectal mucosa in Crohn's disease. Am J Clin Path 1977;67:550-4.

2. Surawicz CM, Meisel JL, Ylvisaker T, Saunders DR, Rubin CE. Rectal biopsy in the diagnosis of Crohn's disease: value of multiple biopsies and serial sectioning. Gastroenterology 1981;81:66-71.

3. Korelitz Bl. Evidence for Crohn's disease as an extensive process. In: Korelitz BI, ed. Inflammatory Bowel Disease. Experience and Controversy. Littleton: John Wright PSG Inc, 1982:9-14.

4. Fazio VW, McLeod RS. Special surgical approaches to the patient with Crohn's disease. In: Kodner IJ, Fry RD, Roe JP, eds. Colon, Rectal and Anal Surgery. Current Techniques and Controversies. St Louis: CV Mosby Company, 1985:243-67.

5. Stahlgren LH, Ferguson LK. The results of surgical treatment of chronic regional enteritis. JAMA 1961;175:986-9.

6. Lennard-Jones JE, Stalder GA. Prognosis after resection of chronic regional enteritis. Gut 1967;8:332-6.

7. Atwell JD, Duthie HL, Goligher JC. The outcome of Crohn's disease. $\mathrm{Br} J$ Surg 1965;52:966-72.

8. Barber KW, Waugh JM, Beahrs OH, Sauer WG. Indications for and results of the surgical treatment of regional enteritis. Ann Surg 1962;156:472-82.

9. De Dombal FT, Burton I, Goligher JC. Recurrence of Crohn's disease after primary excisional surgery. Gut 1971;12:519-27

10. Hellers G. Crohn's disease in Stockholm county 1955-74. A study of cation than a nonperforating indication, such as obstruction.

\section{CONCLUSIONS}

The present investigation showing more frequent repeated resections in patients with an internal fistula is consistent with the concept emerging from these different studies - that clinically distinct patterns of $\mathrm{CD}$ exist, at least in patients with disease of the small intestine. These include a relatively aggres-

epidemiology. Results of surgical treatment and long-term prognosis. Acta Chir Scand 1979;Suppl 490:31-48.

11. Greenstein AJ, Sachar DB, Pasternack BS, Janowitz HD. Reoperation and recurrence in Crohn's colitis and ileocolitis. Crude and cumulative rates. N Engl J Med 1975;293:685-90.

12. Rutgeerts P, Geboes K, Vantrappen G, Kerremans R, Coenegrachts JL, Coremans G. Natural history of recurrent Crohn's disease at the ileocolonic anastomosis after curative surgery. Gut 1984;25:665-72.

13. Whelan G, Farmer RG, Fazio VW, Goormastic M. Recurrence after surgery in Crohn's disease. Relationship to location of disease (clinical pattern) and surgical indication. Gastroenterology 1985;88:1826-33.

14. Owen DA. Pathology of ulcerative colitis and Crohn's disease. In: Freeman HJ, ed. Inflammatory Bowel Disease, vol 1. Boca Raton: CRC Press, 1989:157-74.

15. Binder H, Freeman $\mathrm{HJ}$. Granulomatous (Crohn's) appendicitis. Can J Gastroenterol 1991;5:112-7.

16. Simmonds SD, Noble MA, Freeman HJ. Gastrointestinal features of Yersinia enterocolitica infection. Gastroenterology 1987;92:112-7.

17. Noble MA, Fletcher K, Freeman HJ. Yersinia enterocolitica associated enteric disease. In: Freeman HJ, ed. Inflammatory Bowel Disease, vol 2. Boca Raton: CRC Press, 1989:85-9.

18. Kelly MT, Champagne S, Sherlock $\mathrm{CH}$, Noble MA, Freeman HI, Smith JA. Performance of a commercial latex agglutination test for detection of Clostridium difficile associated diarrhea. J Clin Microbiol 1987;25:1244-7.

19. Freeman HJ. Antibiotic-associated colitis and the role of Clostridium difficile in inflammatory bowel disease. In: Freeman HJ, ed. Inflammatory Bowel Disease, vol 2. Boca Raton: CRC Press, 1989:129-40. sive perforating type and a more indolent, nonperforating or stenosing type. These two clinical forms of CD appear to retain their identities between repeated resections and seem to influence the speed of repeated resection (36). Further prospective studies are required to evaluate the possible consequences of these multiple clinical patterns of $\mathrm{CD}$ and determine if therapeutic modalities can influence the course of the disease in its different forms.

20. Gilks B, Hegedus C, Freeman HJ, Fratkin L, Churg A. Malignant peritoneal mesothelioma after remote abdominal radiation. Cancer 1988;61:2019-21.

21. Kwan WCP, Freeman HJ. Signet ring cell carcinoma of the colon radiologically simulating ileocecal tuberculosis. Can J Gastroenterol $1992 ; 6: 341.4$.

22. Lennard-Jones JE, Stadler GA. Prognosis after resection of chronic regional ileitis. Gut 1967;8:332-6.

23. Greenstein AJ, Sachar DB, Pasternack BS, Janowitz HD. Reoperation and recurrence in Crohn's colitis and ileocolitis. Crude and cumulative rates. N Engl J Med 1975;293:685-90.

24. Truelove SC, Pena AS. Course and prognosis of Crohn's disease. Gut 1976;17:192-201.

25. Sachar DB, Wolfson DM, Greenstein AJ, Goldberg J, Styczynski R, Janowitz HD. Risk factors for postoperative recurrence of Crohn's disease. Gastroenterology 1983;85:917-21.

26. Rutgeerts P, Geboes K, Vantrappen G, Beyls J, Kerremans R, Hiele M. Predictability of the postoperative course of Crohn's disease. Gastroenterology 1990;99:956-63.

27. Lock MR, Farmer RG, Fazio VW, Jagelman DG, Lavery IC, Weakley FL. Recurrence and reoperation for Crohn's disease. The role of disease location in prognosis. $\mathrm{N}$ Engl J Med 1981;304:1586-8.

28. De Dombal FT, Burton I, Goligher JC. The early and late results of surgical treatment for Crohn's disease. Br J Surg 1971;58:805-16.

29. Gehan EA. A general Wilcoxon test for comparing arbitrarily singly censored samples. Biometrika 1965;52:203-23.

30. Peto R, Rike MC, Armitage P, et al. Design and analysis of randomized clinical trials requiring prolonged observation. II. Analysis and samples. Br J Cancer 1977;35:1-39.

31. Mekhjian HS, Switz DM, Watts HD, Deren JJ, Katon RM, Beman FM. 
National Cooperative Crohn's Disease Study: factors determining recurrence of Crohn's disease after surgery.

Gastroenterology 1979;77:907-13.

32. Wettergren A, Christiansen J. Risk of recurrence and reoperation after resection for ileocolic Crohn's disease. Scand J Gastroenterol 1991;26:1319-22.

33. Higgens CS, Allan RN. Crohn's disease of the distal ileum. Gut 1980;21:933-40.

34. Chardavoyne R, Flint GW, Pollack S, Wise L. Factors affecting recurrence following resection for Crohn's disease. Dis Colon Rectum 1986;29:495-502.

35. Basilisco G, Campanini M, Cesana B, Ranzi T, Bianchi P. Risk factors for first operation in Crohn's disease. Am J Gastroenterol 1989;84:749-52.

36. Greenstein AJ, Lackman P, Sachar DB, et al. Perforating and non-perforating indications for repeated operations in Crohn's disease: evidence for two clinical forms. Gut 1988;29:588-92. 


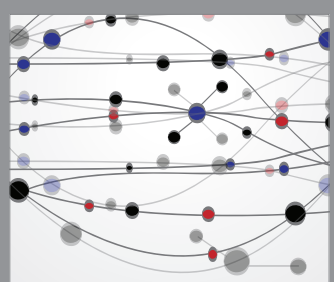

The Scientific World Journal
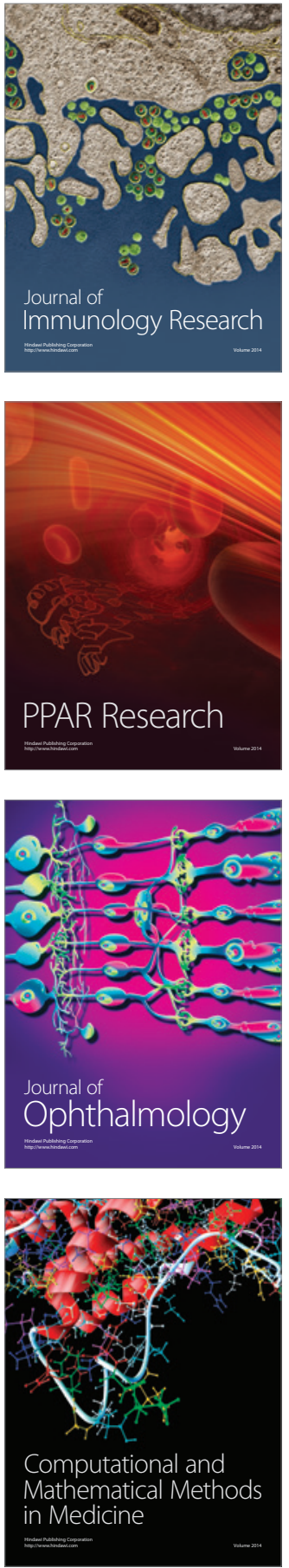

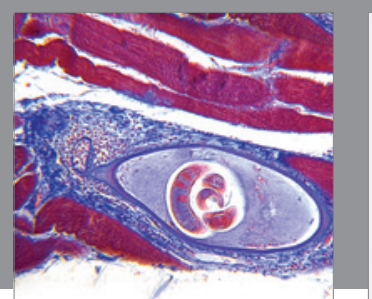

Gastroenterology Research and Practice

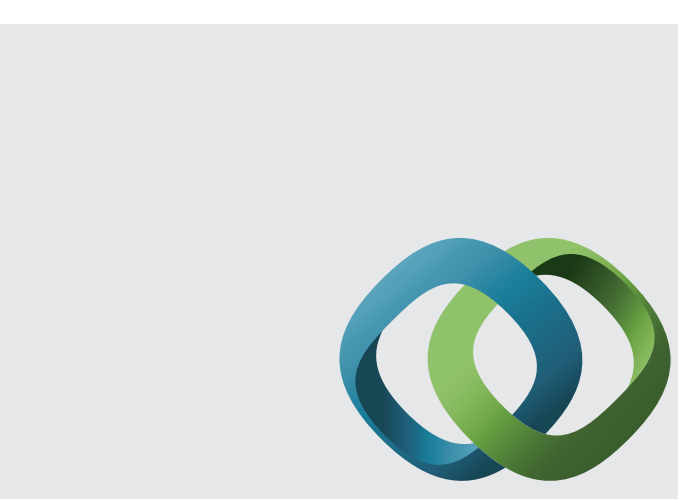

\section{Hindawi}

Submit your manuscripts at

http://www.hindawi.com
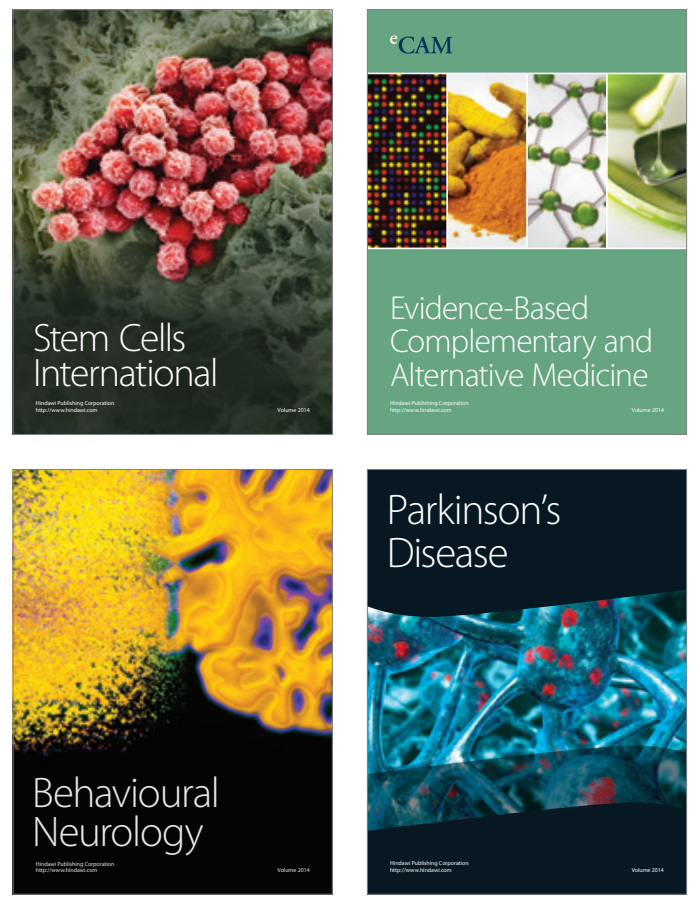
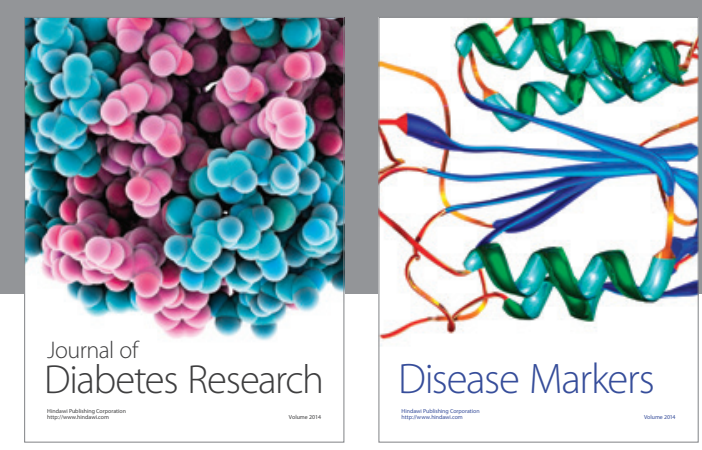

Disease Markers
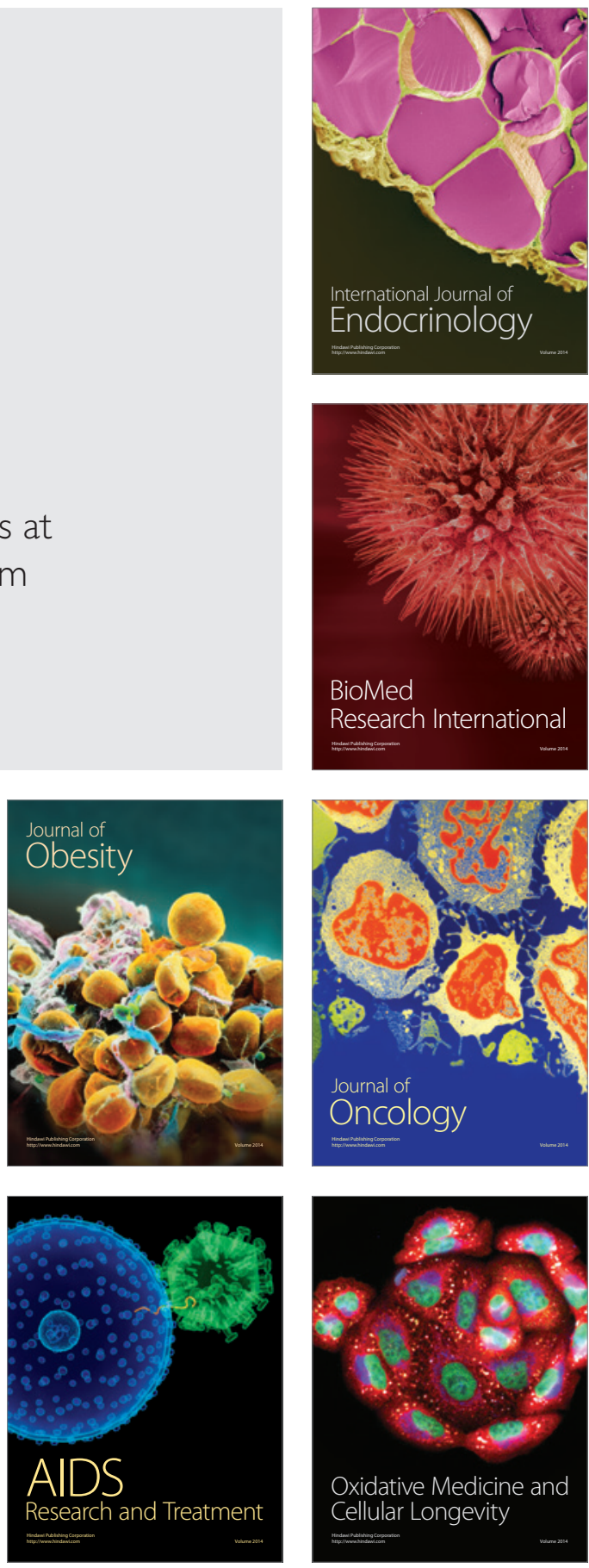